\title{
Amiodarone Modulation of Intracellular Transport of Calcium Ions in Cardiomyocites
}

\author{
Sergey Afanasiev, Dina Kondratyeva, Sergey Popov, Roman Batalov
}

Federal State Budgetary Institution Research Institute for Cardiology of Siberian Branch under the Russian Academy of Medical Sciences, Tomsk, Russia.

Email: dina@cardio.tsu.ru

Received March $16^{\text {th }}, 2012$; revised April 26 ${ }^{\text {th }}, 2012$; accepted May $20^{\text {th }}, 2012$

\begin{abstract}
The influence of amiodarone on intracellular transport of calcium ion in cardiomyocytes of rat was investigated. The experiments were performed on isolated papillary muscles of Wistar rats. Force-frequency dependence $(0.7,1,2,3,4$ $\mathrm{Hz}$ ), extrasystolic and postextrasystolic contractions and post-rest (4-60 s) reactions of rat myocardium after amiodarone treatment $(1 \mu \mathrm{M})$ were investigated. Decay potentiation coefficient of contraction force was estimated. Results: The analyses of force-frequency dependence has shown that amiodarone prevent the decreasing of the force contraction at increasing of the stimulation frequency. Amiodarone promotes increase of the time constant $t_{1}\left(T_{50}\right)$, that indicate the drug promotes acceleration of $\mathrm{Ca}^{2+}$ transport inside the SR resulting increase of $\mathrm{Ca}^{2+}$ in the places of its release from the sarcoplasmic reticulum (SR). Treatment of papillary muscle with amiodarone decreased amplitude of extrasystolic contractions. As known, postextrasystolic and post-rest reactions of myocardium characterize the SR function. We have found amiodarone increased potentiation of postextrasystolic and post-rest contractions. Preliminary caffeine perfusion of muscles preparations cancelled the amiodarone-induced increasing postextrasystolic and post-rest potentiation. However, potentiation decay coefficient before and after treatment with amiodarone didn't have difference. Conclusions, amiodarone influences on intracellular calcium ions homeostasis by modulation SR functions related with most likely are stipulated either by activation of $\mathrm{Ca}^{2+}$ transport from uptake sites to release sites or by prevent of $\mathrm{Ca}^{2+}$ leakage from the SR.
\end{abstract}

Keywords: Amiodarone; Sarcoplasmic Reticulum Function; Postextrasystolic and Post-Rest Contractions; Papillary Muscles of Rat

\section{Introduction}

The wide use of amiodarone in clinical practice is defined by its efficacy and low proarrhythmic activity in comparison with other antiarrhythmic drugs [1,2]. The mechanism of action of amiodarone is based on its ability to influence trans-membrane ion currents. Amiodarone belongs to a class of drugs called Vaughn-Williams Class III antiarrhythmic agents, which mechanism of action is stimulated by inhibition of outward potassium channels, leading to prolongation of transmembrane action potential (AP) $[3,4]$. AP prolongation leads to increase in the effective refractory period in cardiomyocytes of ventricles, atrias, atrioventricular node, accessory pathways and prolongation of QT-interval on ECG $[5,6]$. Along side with that, its pharmacological effects are not restricted with blockade of potassium channel, but have a complex influence on electric parameters of the cardiomyocytes membranes [7]. Amiodarone is able to inhibit partially sodium and calcium channels as well as to block $\beta$-adrenoceptors [5-11]. It's considered that this antiarrhythmic drug shows high antiarrhythmic efficacy owing to these properties. Besides, long-term use of this drug exerts hypothyroid effect. Chronic use of amiodarone influences on the expression of potassium channels genes [7]. Probably, this property of amiodarone could lead to "antiarrhythmic" remodeling of cardiomyocyties. At the same time, not all effects of amiodarone could be explained by above mentioned mechanisms. We suggest that use of amiodarone influences electromechanical coupling processes. Key link of electromechanical coupling is the sarcoplasmic reticulum (SR), which maintains intracellular balance of calcium ions [12-16]. Features of electromechanical coupling organization define dependence between frequency and force of myocardial contraction [17-19]. Therefore, to investigate functional activity of the SR in cardiomyocites the methodical approaches based on analysis of frequency-force dependence are used. In present study we investigated the in- 
fluence of amiodarone on intracellular transport of calcium ion in cardiomyocytes of rat.

\section{Materials and Methods}

\subsection{Subject}

The experiments were performed on papillary muscles rapidly isolated from left ventricle of 44 male Wistar rats $(200-220 \mathrm{~g})$. All procedures with the experimental animals were performed in accordance with the National Guidance on the Operation of the experimental animals (1977).

The curves of isometric contractions of papillary muscles were registered. For this one end of the muscle was fixed to the wall of the thermostatic perfusion chamber and the other end was attached to the rod of the isometric force transducer (mechanoelectric transducer 6MX1C). The muscles were perfused with Krebs-Henseleit solution with following composition (in $\mathrm{mM}$ ): $\mathrm{NaCl}, 120$; $\mathrm{KCl}, 4.8 ; \mathrm{CaCl}_{2}, 2.0 ; \mathrm{MgSO}_{4}, 1.2 ; \mathrm{KH}_{2} \mathrm{PO}_{4}, 1.2 ; \mathrm{NHCO}_{3}$, 20.0; and glucose, 10.0. Carbogen $\left(95 \% \mathrm{O}_{2}\right.$ and $\left.5 \% \mathrm{CO}_{2}\right)$ was used to oxygenate the solution. Stimulation of muscles was performed with 5-ms rectangular electrical impulses applied to two massive silver electrodes. Frequency of stimulating pulses was $0.5 \mathrm{~Hz}$. Experiments have been carried out with muscle being capable to develop at least one-half of the calibration signal (which corresponds to $1 \mathrm{~V}$ ) to the end of the adaptation period (60 min).

\subsection{Experimental Protocols}

Force-frequency dependence. After achieving a stable contractile response of muscle preparation at basic stimulation the frequency of the stimulating impulses was switched discretely on $0.7,1,2,3$, and $4 \mathrm{~Hz}$. Action of each of used frequencies was 1 minute. During this time the contractile response of the muscles was stabilized at the new frequency mode. Dependence of frequencyforce was defined as the relationship between the frequency of stimulating impulses and the corresponding amplitude of regular contraction.

Extrasystolic test. The excitability of the sarcolemma was estimated by changes in the contraction-relaxation cycle in response to an extrasystolic (extraordinary) stimulus. The ability of the SR to accumulate calcium ions in the time of extrasystolic excitation were estimated by change in the postextrasystolic contraction. Extrasystolic contraction was caused by application of the extraordinary electrical pulse with duration of $0.2-1.5 \mathrm{sec}$ from the start of the regular cycle. Amplitude of extrasystolic (EC) and postextrasystolic (PEC) contraction was measured and expressed as a percentage of the amplitude of the regular cycle. The dependence of changes in the am- plitude of EC and PEC on duration of extrasystolic interval was analyzed [20].

Post-rest test. The post-rest test is based on comparative analysis of the curves of regular contractions before and after a short $(4-60 \mathrm{~s})$ interruption of electrical stimulation (a rest period). This test allows to estimate the ability of the cardiomyocyte SR to take up and to release calcium ions in the time of a single contractionrelaxation cycle. In each case the amplitude of the first contraction after rest was expressed in percentage to regular contraction.

Calculation of the recirculating fraction of intracellular $\mathrm{Ca}^{2+}$ was carried out using fall coefficient of contraction force after rest period of $60 \mathrm{~s}$. To make this the amplitude of the n-th contraction was plotted on ordinate axe and value of $(n+1)$-th contraction was plotted on abscissa. The slope of the regression line obtained by these ways was decay coefficient of contraction force [21,22].

The effect of amiodarone was estimated by change in the inotropic response of the myocardium after perfusion of the muscles with a solution containing $1 \mu \mathrm{M}$ amiodarone.

All data are presented as mean \pm SD. Statistical significant of obtained results was estimated by nonparametric Wilcoxon's criterion.

\section{Results}

\subsection{Influence of Amiodarone on Force-Frequency Dependence in Intact Myocardium}

Our study showed negative dependence between frequency and force of contractions of intact rat papillary muscle (Figure 1). Increase of contraction frequency was accompanied with decrease of their amplitude. Treatment of papillary muscles with amiodarone changed the forcefrequency dependence (Figure 1). Although drug itself has weak negative inotropic effect, contraction amplitude at carrying out of electrophysiological action was statistically significant much higher than in control group (Figure 1). At the same time decrease of contraction amplitude at increasing of stimulation frequency was significantly lower, amiodarone prevented decrease of contractility at increasing of stimulation frequency. So, significant difference in contraction amplitude of muscles treated and untreated with amiodarone was observed at contraction frequency of $1 \mathrm{~Hz}$. Contraction amplitude muscles treated with amiodarone at stimulation frequency of $4 \mathrm{~Hz}$ corresponded to amplitude of control muscles at stimulation frequency of $1 \mathrm{~Hz}$.

Velocity parameters of contraction-relaxation cycle were increased with increasing of contraction amplitude on the background of amiodarone (Table 1). 


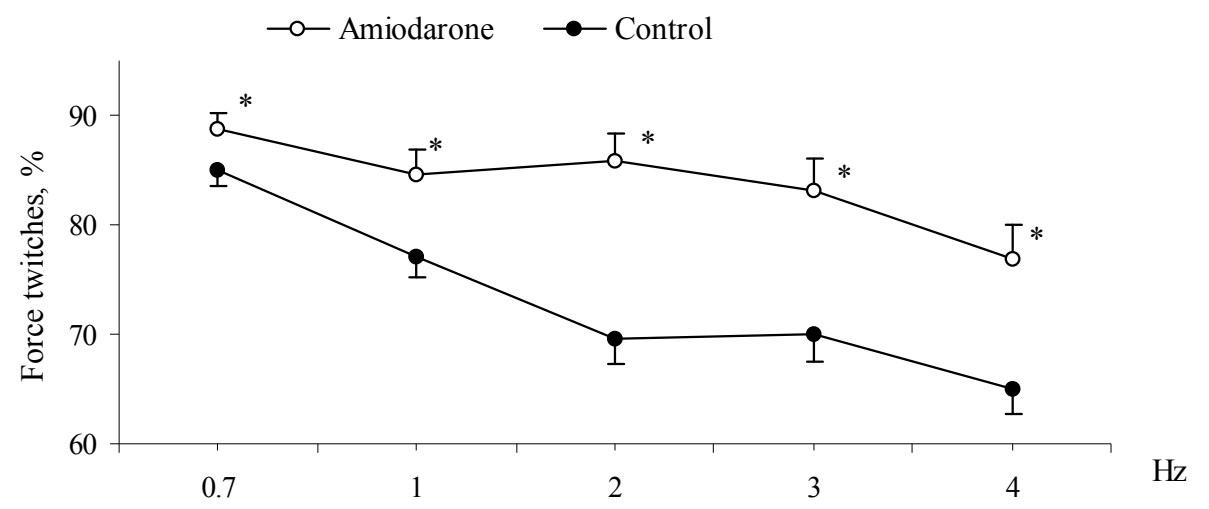

Figure 1. Force-frequency dependence of rat papillary muscles before and after amiodarone treatment. Contractile force of the muscles is expressed as s percentage of steady state twitches at $0.5 \mathrm{~Hz}$. *Significant difference $(\mathrm{p}<0.01)$ from control.

Table 1. Alterations of contraction-relaxation cycle parameters of rat papillary muscle after amiodarone treatment $(\mathrm{M} \pm$ SEM).

\begin{tabular}{|c|c|c|c|c|c|c|c|}
\hline \multirow{2}{*}{ Experimental groups } & \multirow{2}{*}{$\mathrm{n}$} & \multirow{2}{*}{ Cycle parameters } & \multicolumn{5}{|c|}{ Frequency, Hz } \\
\hline & & & 0.7 & 1 & 2 & 3 & 4 \\
\hline \multirow{3}{*}{ Control } & \multirow{3}{*}{18} & $+\mathrm{dT} / \mathrm{dt}$ & $90.4 \pm 2.6$ & $81.6 \pm 2.7$ & $82.4 \pm 4.2$ & $90.5 \pm 4.3$ & $86.5 \pm 3.0$ \\
\hline & & $-\mathrm{dT} / \mathrm{dt}$ & $88.7 \pm 2.1$ & $77.4 \pm 2.7$ & $74.7 \pm 3.6$ & $83.7 \pm 3.7$ & $77.3 \pm 3.0$ \\
\hline & & $\mathrm{t}$ & $95.6 \pm 2.7$ & $94.1 \pm 2.5$ & $89.7 \pm 3.0$ & $79.8 \pm 2.1$ & $76.1 \pm 2.3$ \\
\hline \multirow{3}{*}{ Amiodarone $(1 \mu \mathrm{M})$} & \multirow{3}{*}{9} & $+\mathrm{dT} / \mathrm{dt}$ & $\begin{array}{l}90.4 \pm 1.5 \\
p=0.706\end{array}$ & $\begin{array}{l}87.7 \pm 2.3 \\
p=0.187\end{array}$ & $\begin{array}{c}108.1 \pm 2.4^{*} \\
\mathrm{p}=0.004\end{array}$ & $\begin{array}{c}105.3 \pm 2.9 \\
p=0.069\end{array}$ & $\begin{array}{c}104.0 \pm 3.2^{*} \\
\mathrm{p}=0.015\end{array}$ \\
\hline & & $-\mathrm{dT} / \mathrm{dt}$ & $\begin{array}{l}91.1 \pm 1.5 \\
p=0.480\end{array}$ & $\begin{array}{c}88.5 \pm 2.3^{*} \\
\mathrm{p}=0.048\end{array}$ & $\begin{array}{c}92.8 \pm 2.4^{*} \\
\mathrm{p}=0.021\end{array}$ & $\begin{array}{l}96.1 \pm 2.9 \\
p=0.069\end{array}$ & $\begin{array}{l}92.4 \pm 3.2 \\
p=0.071\end{array}$ \\
\hline & & $\mathrm{t}$ & $\begin{array}{c}100.7 \pm 1.5 \\
\mathrm{p}=0.334\end{array}$ & $\begin{array}{l}95.5 \pm 2.3 \\
p=0.480\end{array}$ & $\begin{array}{l}90.4 \pm 2.4 \\
p=0.912\end{array}$ & $\begin{array}{l}86.6 \pm 2.9 \\
p=0.065\end{array}$ & $\begin{array}{l}83.1 \pm 3.2 \\
p=0.108\end{array}$ \\
\hline
\end{tabular}

Note: $+\mathrm{dT} / \mathrm{dt}$ : maximum velocity of peak tension, $-\mathrm{dT} / \mathrm{dt}$ : maximum velocity of decay tension, $\mathrm{t}$ : contraction-relaxation cycle time. All values expressed in percentage of steady state contraction. * Significant difference from control value.

\subsection{Influence of Amiodarone on Amplitude of Extrasystolic and Postextrasystolic Contraction of Myocardium}

To assess work of $\mathrm{Ca}^{2+}$-transporting systems of the cardiomyocytes we used methodic approach connected with analysis of inotropic response of isolated perfused rat papillary muscles on extraordinary (extrasystolic) stimulating pulses [23-25]. Action on a muscle with extrasystolic (extraordinary) pulse causes additional inotropic response - extrasystolic contraction (EC). In dependence on duration of interval between regular and extraordinary stimulus (extrasystolic interval) extraordinary stimulating pulse decays within different phases of cardiomyocytes AP, that is reflected in structure of extrasystolic contraction. Our study showed that extraordinary stimulus applied on rat papillary muscles after $0.25 \mathrm{~s}$ led to appearance of independent contraction. At this prolongation of extrasystolic interval caused increase of amplitude of extrasystolic contractions (Figure 2).

Treatment of papillary muscle of intact rats with amiodarone decreased significant $(\mathrm{p}<0.05)$ amplitude of extrasystolic contractions in comparison with the control (Figure 2). At this time constant $t_{1}\left(T_{50}\right)$ representing extrasystolic interval corresponding to extrasystolic contraction equal to the half of regular contraction increased, too. So, if value of $t_{1}\left(T_{50}\right)$ in control was $0.42 \pm 0.022 \mathrm{~s}$, on the background of amiodarone the value of this parameter increases up to $0.50 \pm 0.023 \mathrm{~s}(\mathrm{p}<0.05)$ (Table 2).

It is known that caffeine inhibits SR function. Its use in our study showed that caffeine rendered pronounced potentiating action on amplitude of extrasystolic contractions which values increased on $10 \%-15 \%(p<0.05)$ in comparison with control value (Figure 2). Value $t_{1}\left(T_{50}\right)$ in presence of caffeine decreased to $0.27 \pm 0.045 \mathrm{~s}$ (p < 0.01) (Table 2). On this background treatment with amiodarone made no influence on inotropic effect of extrasystolic action. This fact shows, that amiodarone effects on contraction-relaxation cycle parameters could be produced not only through ion-transportation channels of external membrane, but by modification of SR functions, too. 


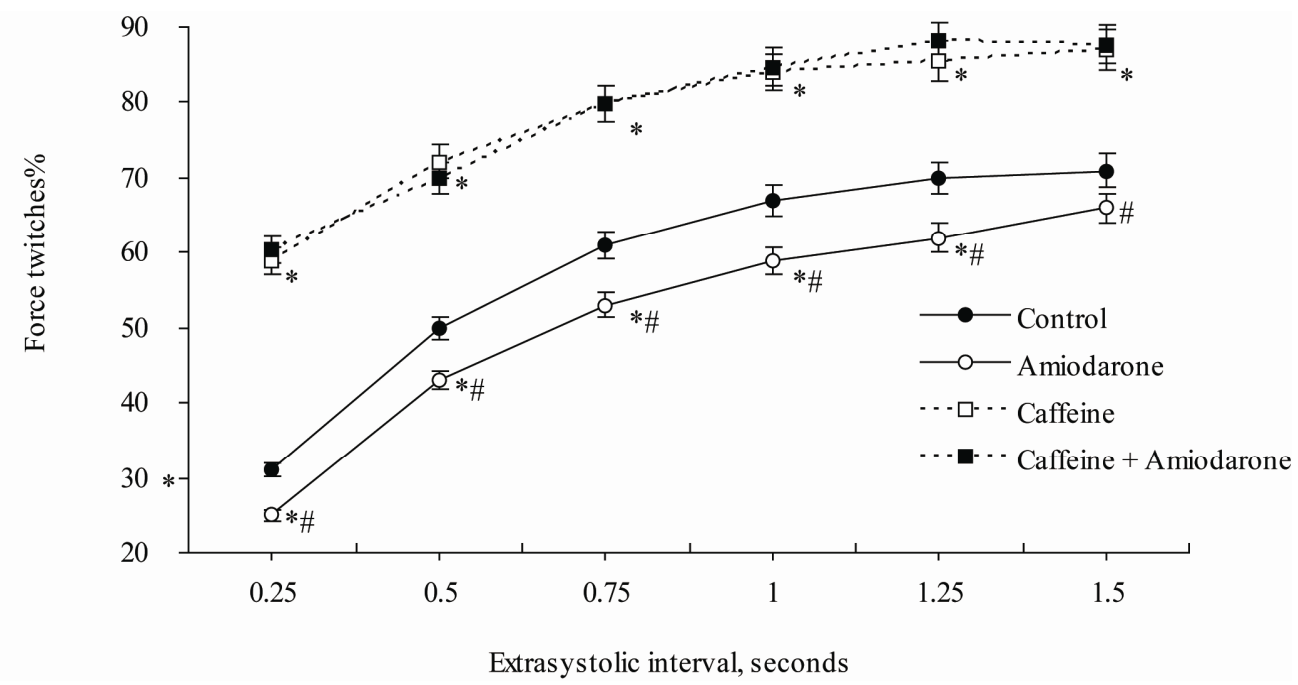

Figure 2. Extrasystolic twitch force of rat papillary muscles before and after amiodarone and caffeine treatment. Extrasystolic contraction amplitude is expressed as percentage of steady state contractions. *Significant difference $(p<0.01)$ from control. \#Significant difference $(\mathrm{p}<\mathbf{0 . 0 1})$ between Amiodarone and Caffeine + Amiodarone.

Table 2. Amiodarone influence on $t_{1}\left(T_{50}\right)$ of rat papillary muscle $(M \pm m)$.

\begin{tabular}{|c|c|c|c|c|}
\hline Experimental groups & Control $\mathrm{N}=57$ & Amiodarone $\mathrm{N}=12$ & Caffeine $\mathrm{N}=12$ & Amiodarone + Caffeine $\mathrm{N}=10$ \\
\hline $\mathrm{t}_{1}\left(\mathrm{~T}_{50}\right)$ & $0.42 \pm 0.022$ & $0.50 \pm 0.023^{*}$ & $0.27 \pm 0.045^{*}$ & $0.30 \pm 0.058^{*}$ \\
\hline
\end{tabular}

Note: $\mathrm{t}_{1}\left(\mathrm{~T}_{50}\right)$ - extrasystolic interval, corresponding to EC amplitude that equal to the half of regular contraction. *Significant difference (p $\left.<0.05\right)$ from control value.

Extrasystolic action is characterized not only by appearance of extrasystolic contraction, but and change in parameters of next regular contraction-relaxation cyclepostextrasystolic contraction (PEC) $[25,26]$. In our control studies amplitude of postextrasystolic cycle contraction-relaxation on extrasystolic intervals $0.2-0.5 \mathrm{~s} \mathrm{ex}-$ ceeded the amplitude of basic contractions. Extraordinary stimulus, applied after 0.75 and more seconds did not cause increase of the amplitude of extrasystolic contraction and even, conversely, led to a little decrease of extrasystolic contraction. Treatment of myocardium with amiodarone increased potentiation of postextrasystolic contraction on extrasystolic intervals $0.2 \mathrm{~s}$ and $0.225 \mathrm{~s}(\mathrm{p}$ $<0.01$ ) (Figure 3). Maximum effect has been obtained at extrasystolic interval $0.225 \mathrm{~s}(123.8 \% \pm 1.52 \%$ and $135.7 \% \pm 2.62 \%$, control and amiodarone, correspondingly). Potentiation effect of postextrasystolic inotropic response of myocardium is connected with ejection of additional large concentration of $\mathrm{Ca}^{2+}$ from the SR to myoplasm. It becomes possible due to previous storing of $\mathrm{Ca}^{2+}$ in the SR entered to myoplasm from extracellular space during extraordinary contraction $[24,25]$.

It is considered, that expression of postextrasystolic contraction potentiation reflects ability of the cardiomyocytes SR to accumulate additional amounts of $\mathrm{Ca}^{2+}$. Increasing of PEC potentiation after treatment of rat papillary muscles with amiodarone demonstrates that the SR contains more calcium ions than the control (Figure 3). Treatment of muscles preparations with caffeine was accompanied with cancellation of postextrasystolic potentiation on the background of amiodarone. On this background amiodarone's potentiation effect was completely neutralized (Figure 3). These results testify that amiodarone effect on postextrasystolic potentiation is realized due to modulation of SR functional activity. Amiodarone effect, probably, is related to it's ability to accelerate calcium ions transport from places of capture to places of SR releasing taking into account its influence on time constant $t_{1}\left(T_{50}\right)$, furthermore, amiodarone, most likely, promotes limitation the calcium ions leakage current from the SR.

\subsection{Influence of Amiodarone on a Post-Rest Potentiation and Mechanical Restitution}

Inotropic response of papillary muscles of the muscles strips on short-term delay and following renewal of electrical stimulation ("post-rest" test) characterizes the SR ability to accumulate and to store calcium ions [27,28]. Phenomenon of the increment of amplitude - potentialtion of contraction response on such action is connected with accumulation of calcium ions in the SR terminal structures at the rest period in the cardiomyocytes. After renewal of electrical stimulation of muscles the greater 
concentration of $\mathrm{Ca}^{2+}$ takes part in realization of the first contraction that provides increase in registered contraction amplitude [29]. Our experiment on intact rats myocardium showed, that in all used rest periods the amplitude of first contraction exceeded basic level (Figure 4) Maximum amplitude increment in intact muscles after 60 $\mathrm{s}$ rest period was $87.8 \% \pm 12.12 \%$. However, the amplitude increment speed $(\mathrm{T})$ after 30 and $60 \mathrm{~s}$ rest periods significantly decreased. This fact testifies the saturation of the SR with calcium ions and greater amount of calcium ejected from the SR in the time of contraction.

The same impacts used on muscles treated with amiodarone resulted in reliable potentiation strengthening $(\mathrm{p}<$ 0.01). As it is shown on Figure 4 intensity of this effect was increased with increasing of rest period. However, $\mathrm{t}\left(\mathrm{T}_{50}\right)$ index calculated for intact and amiodarone treated muscles hadn't significant differences and was $11.87 \pm$ 0.761 and $10.56 \pm 0.637 \mathrm{~s}$, respectively. This fact shows that after treatment of muscles with amiodarone the speed of the $\mathrm{Ca}^{2+}$ uptake from cardiomyocyte myoplasm into the SR didn't change. Taking into account existing conceptions about influence of "post-rest" test on SR condition we can suggest, that amiodarone promotes more effective "holding" of $\mathrm{Ca}^{2+}$ in the SR and/or prevents free $\mathrm{Ca}^{2+}$ leakage current from the SR and does not change SR $\mathrm{Ca}^{2+}$-ATPase activity.

Treatment of intact papillary muscles with caffeine results in canceling of inotropic reaction potentiation on

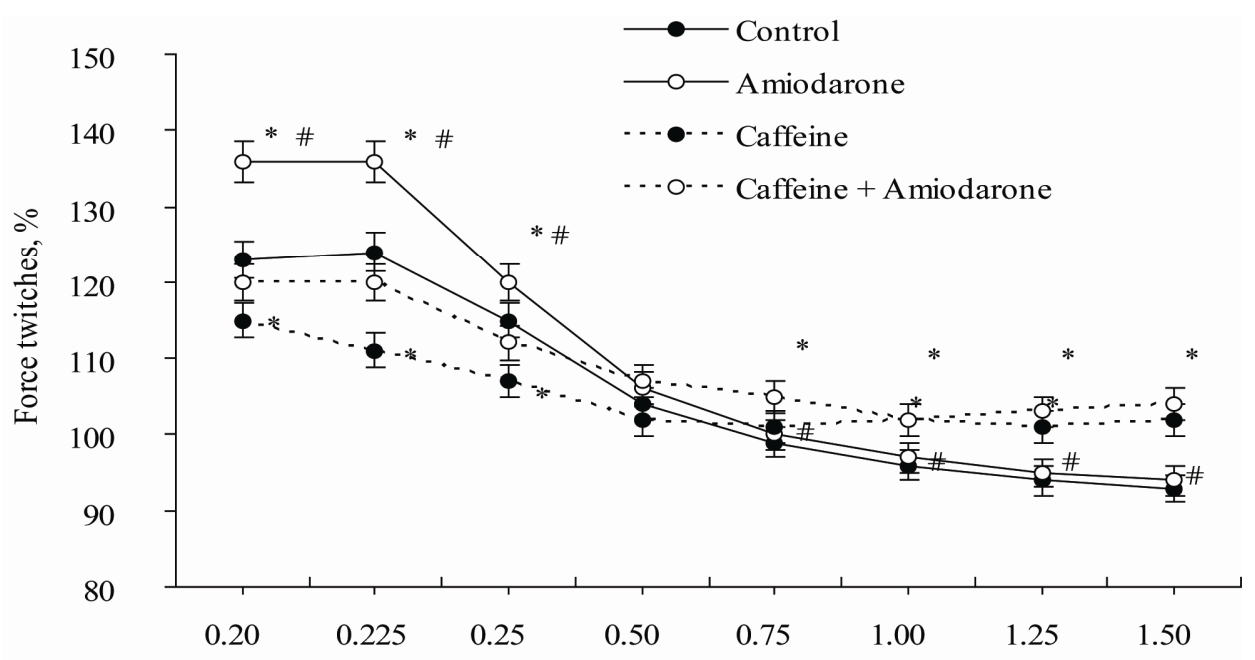

Extrasystolic interval, seconds

Figure 3. Influence of caffeine and amiodarone on postextrasystolic twitches amplitude of rat's papillary muscles. Postextrasystolic contraction amplitude is expressed as percentage of steady state contractions. *Significant difference $(p<0.01)$ comparing to Control. \#Significant difference $(\mathbf{p}<0.01)$ between Amiodarone and Caffeine + Amiodarone.

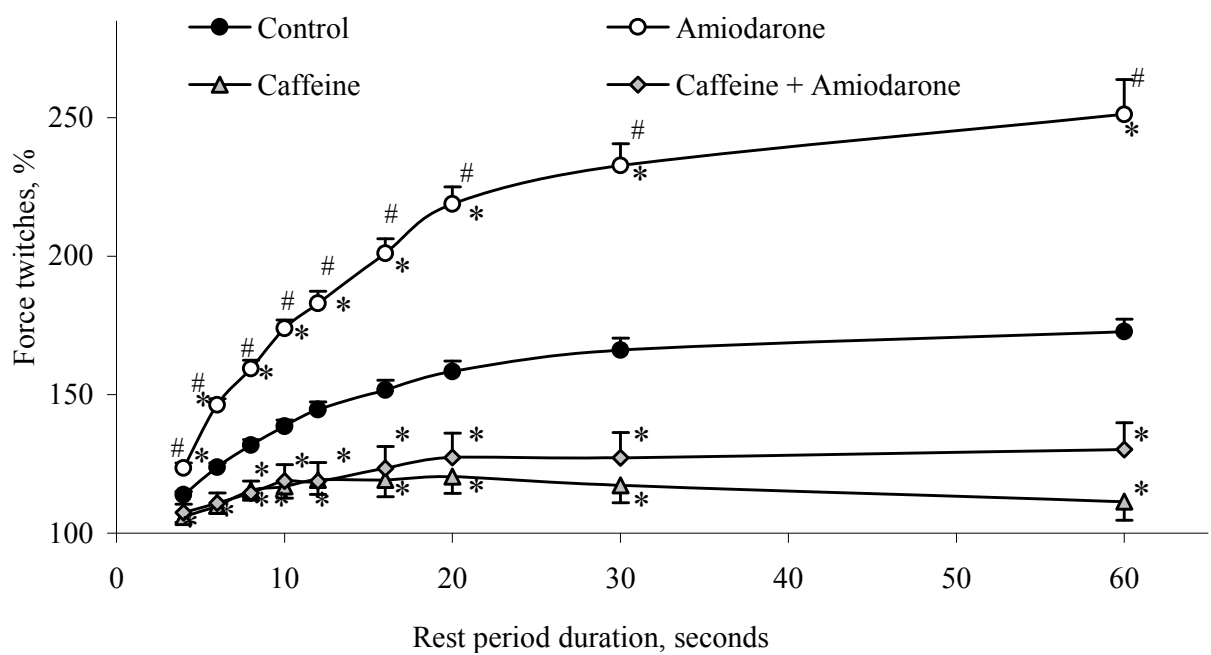

Figure 4. Effect of amiodarone and caffeine on mechanical restitution of rat papillary muscles. *Significant difference (p $<$ $0.01)$ comparing to control. \#Significant difference $(p<0.01)$ between Amiodarone and Caffeine + Amiodarone. 
the rest periods (Figure 4). This figure shows that in muscles treated with caffeine already after $20 \mathrm{~s}$ rest period restitution curve begins to decrease. These results point out that after caffeine action the SR capacity, as an intracellular $\mathrm{Ca}^{2+}$ depot, decreases and depletion happens already at the $20 \mathrm{~s}$ rest period. On the background of developed caffeine effects, treatment of muscles with amiodarone didn't provide recovery of "normal" muscle reaction on post-rest test action (Figure 4). However, amiodarone eliminates depletion of the $\mathrm{Ca}^{2+}$ pool, located in the SR. On background of caffeine amiodarone prevents $(p<0.05)$ suppression of contraction muscle response after rest period of 20 and more seconds. Listed data agrees to our concept, that amiodarone potentiating effect on inotropic reactions of papillary muscles during "postrest" test is connected with the SR functional activity.

Another index of intracellular $\mathrm{Ca}^{2+}$ recirculation is assessment of recovery of basic muscle contractility after "post-rest" test $[21,22,28]$. Recirculation of intracellular $\mathrm{Ca}^{2+}$ fraction on isolated muscles is estimated by potentiation decay coefficient (DPC). This index is calculated from the curve of amplitude linear regression of " $\mathrm{n}$ th" contraction against next " $\mathrm{n}+1^{\text {st" }}$ contraction $[21,22]$. In our study recovery of amplitude up to basic values happened to the 9-th contraction both in a control conditions and on amiodarone background (Figure 5).

It turned out, that DPC in control and after treatment with amiodarone didn't show significant difference $(62.9 \%+2.85 \%$ and $64.1 \%+3.31 \%)$. This result shows that both in intact heart muscle and in one treated with amiodarone up to $62 \%$ of calcium ions from myoplasm is resequestered back to the SR, and 38\% - is ejected into extracellular spaces by $\mathrm{Na}^{+} / \mathrm{Ca}^{2+}$-exchanger $[21,22]$. These results agree with previous analysis of the results and show, that amiodarone do not influence on the SR $\mathrm{Ca}^{2+}$-ATPase activity.

\section{Discussion}

It is shown in experiment that myocardium cells have a homeostatic mechanism which provides an optimal contraction response in different frequency modes [18,30]. As rule rise of contraction frequency leads to increase of entry of sodium and calcium ions from surroundings into a cell [30]. Positive dependence in increase of contraction force with increase in the frequency of stimulation has been shown for majority of mammalians [31-33]. Exception is the myocardium of rat. A force of rat heart contraction decreases with increasing of stimulation frequency $[33,34]$. Negative force-frequency dependence of isolated rat myocardium by all appearance can be connected with the fact that process of myocardium contraction in this animals is provided, mainly with $\mathrm{Ca}^{2+}$ entering at excitation of cardiomyocites from the SR [34]. In this conditions shortening of intervals between electric stimulus leads to reduction of the time of $\mathrm{Ca}^{2+}$ transporttation from uptake places to release places into the cardiomyocites SR. As a result not all $\mathrm{Ca}^{2+}$ succeeds to reach terminal cisterns to the time of next contraction and to be used in next contraction response [30]. Besides, inactivated $\mathrm{Ca}^{2+}$-channels of cardiomyocytes SR are not recover completely for the short period of time between contractions $[30,35]$. Our study showed, that amiodarone is able to prevent contractility decay at increasing of stimulation frequency in intact rat myocardium, although it has weak negative inotropic effect, that amiodarone induces entry of greater quantity of calcium ions during contraction. Because this antyarrhythmic drug is able to block partially $\mathrm{Ca}^{2+}$ and $\mathrm{Na}^{+}$-channels resulting weak negative inotropic effect, we can exclude possibility of additional income of calcium ions into the cell from extracellular spaces. As it is known, the main calcium pool, taking part in the process of rat cardiomyocytes contraction, is intracellular calcium stored in the SR [34]. Therefore, it is logically to suggest, that amiodarone is able to influence on work of SR $\mathrm{Ca}^{2+}$-transporting systems. Probably, that increase of $\mathrm{Ca}^{2+}$ transportation rate from uptake places to release places inside the structure crease of calcium ions during systole, i.e. mobilization of

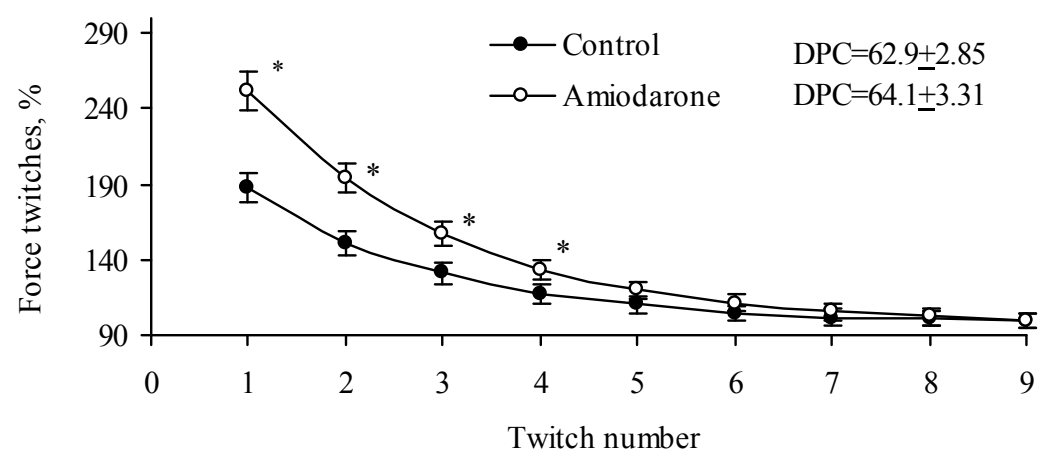

Figure 5. Decay in post-rest potentiation in rat papillary muscle after 60 second rest period. *Value significantly different (0.01) from Control. 
available stock of intracellular $\mathrm{Ca}^{2+}$ takes place. So, our investigations allow to make an assumption that amiodarone is able to influence not only on activity of transmembrane channels and receptors, but to modulate intracellular homeostasis of calcium ions, too.

In addition because of amiodarone promotes increase of the time constant $t_{1}\left(T_{50}\right)$ we can speak that this drug promotes acceleration of $\mathrm{Ca}^{2+}$ transport inside the SR resulting increase of $\mathrm{Ca}^{2+}$ in the places of its release from the SR. Transport of calcium ions inside cardiomyocites SR from uptake places to ejection places and time of $\mathrm{Ca}^{2+}$-channels reactivation is estimated with help of the time constant $\mathrm{t}_{1}\left(\mathrm{~T}_{50}\right)[21,22]$.

According to the literature, the effect of PEC potentiation of inotropic response of cardiac muscle is associated with income of additional $\mathrm{Ca}^{2+}$ into myoplasm from the extracellular space during an extraordinary contraction AP [24]. Calcium ions entered into cardiomyocytes are deposited in the sarcoplasmic reticulum, that increases the SR contribution in the first postextrasystolic cycle of contraction-relaxation. It is believed that the effect of PEC potentiation reflects ability of the sarcoplasmic reticulum of cardiomyocytes to accumulate additional quantity of $\mathrm{Ca}^{2+}$. So, increasing the PEC potentiation after treatment of rat papillary muscles with amiodarone demonstrates the presence of additional calcium ions stored in the SR in comparison with the control, and may be stimulated by increase in functional ability of the SR of cardiomyocytes.

A number of studies carried out using this test showed that the inotropic response of muscle strips on renewal of electrical stimulation after a rest period characterizes ability of the cardiomyocytes SR to accumulate and to hold calcium ions $[21,22,27,28]$. The observed phenomenon of increment of the amplitude in response to renewal of stimulation is connected with the fact that in the rest period dissociation of the $\mathrm{Ca}^{2+}$ complexes with $\mathrm{Ca}^{2+}$ binding proteins promotes inflow of additional calcium ion quantity from the sarcoplasma into the cardiomyocytes SR and increase of $\mathrm{Ca}^{2+}$ level deposited in the terminal cisterns [30]. In addition, increase of the rest interval duration provides the time required to move the calcium ions from the uptake places to places of their release from the SR and, as a consequence, leads an increase of $\mathrm{Ca}^{2+}$ pool in terminal cisterns; later it is released during the first rest period after contraction $[30,35]$. Since the reactivation of $\mathrm{Ca}^{2+}$-channel SR also takes time, increase of rest interval duration between contractions may contribute to increase in activated $\mathrm{Ca}^{2+}$ channels of cell membranes and SR membrane, thus providing a greater number of calcium ions entering into cytosol from the terminal cisterns of reticulum and extracellular space. Perfusion of the muscle strips with amiodarone increased potentiation effect in the whole range of used rest intervals and the saturation threshold of the cardiomyocytes SR with calcium ions that testifies that amiodarone is able to be accumulated and to prevent calcium ion leakage current from the SR.

It is known, that caffeine is used in experimental studies to inhibit functional activity of the cardiomyocytes SR [36,37]. Caffeine effects were connected with partial inhibition of $\mathrm{Ca}^{2+}$-ATPase and blockade of ryanodine receptors in open state that promotes leakage of calcium ions from the SR [38]. Such caffeine action causes short time rise of calcium ions in cardiomyocytes myoplasm and increase of cardiomyocyte contractility, then depletion of intracellular calcium depot and, accordingly, decrease of contraction activity happens [36,38]. In addition, inhibition of amiodarone-induced increment of PEC amplitude and post-rest contraction with caffeine also testify of this hypothesis. Calculation of calcium ions recirculation coefficient from rhythm-inotropic dependence curve allow us to suggest that amiodarone effects on SR function are not related to modulation of SR's $\mathrm{Ca}^{2+}$ ATP-ase, but most likely are stipulated either by activetion of $\mathrm{Ca}^{2+}$ transport from uptake places to ejection places inside this intracellular structure or by limitation of $\mathrm{Ca}^{2+}$ leakage current from the SR.

Thus, our results allow reveal one more property of III class antiarrhythmic drug amiodarone associated with modulation of intracellular calcium ions homeostasis. That property is undoubtedly positive and probably allows to this drug to be high effectiveness in therapy of life-threatening arrhythmias.

\section{REFERENCES}

[1] S. J. Connolly, "Evidence-Based Analysis of Amiodarone Efficacy and Safety," Circulation, Vol. 100, 1999, pp. 2025-2034. doi:10.1161/01.CIR.100.19.2025

[2] L. M. Letelier, K. Udol, J. Ena, B. Weaver and G. H. Guyatt, "Effectiveness of Amiodarone for Conversion of Atrial Fibrillation to Sinus Rhythm: A Meta-Analysis," Archives of Internal Medicine, Vol. 163, No. 7, 2003, pp. 777-785. doi:10.1001/archinte.163.7.777

[3] R. F. Bosch, G. Li, R. Gaspo and S. Nattel, "Electrophysiologic Effects of Chronic Amiodarone Therapy and Hypothyroidism, Alone and in Combination, on Guinea Pig Ventricular Myocytes," The Journal Pharmacology and Experimental Therapeutics, Vol. 289, No. 1, 1999, pp. 156-165.

[4] K. Kamiya, A. Nishiyama, K. Yasui, M. Hojo, M. C. Sanguinetti and I. Kodama, "Short- and Long-Term Effects of Amiodarone on the Two Components of Cardiac Delayed Rectifier $\mathrm{K}^{+}$Current," Circulation, Vol. 103, 2001, pp. 1317-1324. doi:10.1161/01.CIR.103.9.1317

[5] M. D. Freedman and J. C. Somberg, "Pharmacology and Pharmacokinetics of Amiodarone," Journal of Clinical Pharmacology, Vol. 31, 1991, pp. 1061-1069.

[6] I. Kodama, K. Kamiya and J. Toyama, "Cellular Electro- 
pharmacology of Amiodarone" Cardiovascular Research, Vol. 35, No. 1, 1997, pp. 13-29. doi:10.1016/S0008-6363(97)00114-4

[7] I. Kodama, K. Kamiya, H. Honjo and J. Toyama, “Acute and Chronic Effects of Amiodarone on Mammalian Ventricular Cells," Japanese Heart Journal, Vol. 37, No. 5, 1996, pp. 719-730. doi:10.1536/ihj.37.719

[8] P. Chatelain, L. Meysmans, J. R. Mattéazzi, P. Beaufort and M. Clinet, "Interaction of the Antiarrhythmic Agents SR 33589 and Amiodarone with the Beta-Adrenoceptor and Adenylate Cyclase in Rat Heart," British Journal of Pharmacology, Vol. 116, No. 3, 1995, pp. 1949-1956.

[9] V. Drvota, J. Häggblad, I. Blange, Y. Magnusson and S. Sylvén, "The Effect of Amiodarone on the Beta-Adrenergic Receptor Is Due to a Downregulation of Receptor Protein and Not to a Receptor-Ligand Interaction," Biochemical and Biophysical Research Communications, Vol. 255, No. 2, 1999, pp. 515-520. doi:10.1006/bbrc.1998.0138

[10] P. Schnabel, F. Mies, C. Maack, S. Rosenkranz, O. Zolk and M. Böhm, "Beneficial Effects of Amiodarone in Heart Failure: Interaction with Beta-Adrenoceptors rather than G Proteins," European Journal of Pharmacology, Vol. 369, No. 3, 1999, pp. 391-394. doi:10.1016/S0014-2999(99)00101-6

[11] D. P. Zankov, W. G. Ding, H. Matsuura and M. Horie, "Open-State Unblock Characterizes Acute Inhibition of I Potassium Current by Amiodarone in Guinea Pig Ventricular Myocytes," Journal of Cardiovascular Electrophysiology, Vol. 16, No. 3, 2005, pp. 314-322. doi:10.1046/j.1540-8167.2005.40561.x

[12] M. E. Diaz, H. K. Grahama, S. C. O’Neill, A. W. Trafford and D. A. Eisner, "The Control of Sarcoplasmic Reticulum Ca Content in Cardiac Muscle," Cell Calcium, Vol. 38, No. 3-4, 2005, pp. 391-396. doi:10.1016/j.ceca.2005.06.017

[13] A. M. Prasad and G. Inesi, "Analysis of Calcium Transients in Cardiac Myocytes and Assessment of the Sarcoplasmic Reticulum $\mathrm{Ca}^{2+}$-ATPase Contribution," Methods in Molecular Biology, Vol. 798, No. 6, 2012, pp. 411421. doi:10.1007/978-1-61779-343-1 24

[14] A. M. Rubtsov, "Molecular Mechanisms of Regulation of the Activity of Sarcoplasmic Reticulum Ca-Release Channels (Ryanodine Receptors), Muscle Fatigue, and Severin's Phenomenon," Biochemistry (Mosc), Vol. 66, No. 10, 2001, pp. 1132-1143. doi:10.1023/A:1012485030527

[15] H. E. ter Keurs, "Electromechanical Coupling in the Cardiac Myocyte; Stretch-Arrhythmia Feedback," Pflugers Archive, Vol. 462, No. 1, 2011, pp. 165-175. doi:10.1007/s00424-011-0944-3

[16] A. Zarain-Herzberg, J. Fragoso-Medina and R. EstradaAvilés, "Calcium-Regulated Transcriptional Pathways in the Normal and Pathologic Heart," IUBMB Life, Vol. 63, No. 10, 2011, pp. 847-855. doi:10.1002/iub.545

[17] D. M. Bers, "Calcium Cycling and Signaling in Cardiac Myocytes," Annual Review of Physiology, Vol. 70, 2008, pp. 23-49. doi:10.1146/annurev.physiol.70.113006.100455
[18] K. Brixius, M. Pietsch and R. H. G. Schwinger, "The Intracellular $\mathrm{Ca}^{2+}$-Homeostasis Influences the FrequencyDependent Force Generation in Man," Basic Research in Cardiology, Vol. 94, 1999, pp. 152-158. doi: $10.1007 / \mathrm{s} 003950050138$

[19] P. Pucelík, "Pharmacological Blockade of Sarcoplasmic Reticulum Induces a Negative Lusitropic Effect," General Physiology \& Biophysics, Vol. 26, No. 3, 2007, pp. 214-220.

[20] D. S. Kondratyeva, S. A. Afanasyev, M. V. Egorova, T. Yu. Rebrova and S. V. Popov, "Contractile Activity and Energetic Metabolism of Postinfarction Heart against Diabetic Damage in Experiment," The Siberian Medical Journal, Vol. 26, No. 2, 2011, pp. 136-140.

[21] U. Ravens, C. Mahl, A. Ohler, S. M. C. Hardman and M. I. M. Noble, "Mechanical Restitution and Recirculation Fraction in Cardiac Myocytes and Left Ventricular Muscle of Adult Rats," Basic Research in Cardiology, Vol. 91, 1996, pp. 123-130. doi:10.1007/BF00799684

[22] S. N. Wu, A. Y. Shen and T. L. Hwang, "Analysis of Mechanical Restitution and Post-Rest Potentiation in Isolated Rat Atrium," Chinese Journal of Physiology, Vol. 39, 1996, pp. 23-29.

[23] F. D. Marengo, M. T. Marquez, P. Bonazzola and J. E. Ponce-Hornos, "The Heart Extrasystole: An Energetic Approach," American Journal of Physiology, Vol. 276, No. 1, 1999, pp. H309-H316.

[24] T. Tatsumi, J. Asayama, H. Miyazaki, T. Shirayama, I. Omori, D. Inoue and M. Nakagawa, "The Effects of an Extra-Stimulation on Post-Extra-Systolic Potentiation in Papillary Muscle of Rats," Japanese Heart Journal, Vol. 31, No. 3, 1990, pp. 355-363. doi:10.1536/ihj.31.355

[25] D. V. Vassallo, E. Q. Lima, P. Campagnaro, A. N. Faria and J. G. Mill, "Mechanisms Underlying the Genesis of Post-Extrasystolic Potentiation in Rat Cardiac Muscle," Brazilian Journal of Medical \& Biological Research, Vol. 28, No. 3, 1995, pp. 377-383.

[26] J. Mizuno, J. Araki, S. Mohri, H. Minami, Doi Y., W. Fujinaka, K. Miyaji, T. Kiyooka, Y. Oshima, G. Iribe, M. Hirakawa and H. Suga, "Frank-Starling Mechanism Retains Recirculation Fraction of Myocardial $\mathrm{Ca}(2+)$ in the Beating Heart," Japanese Journal of Physiology, Vol. 51, No. 6, 2001, pp. 733-743.

[27] D. M. Bers, "Ca Influx and Sarcoplasmic Reticulum Ca Release in Cardiac Muscle Activation during Postrest Recovery," American Journal of Physiology, Vol. 248, 1985, pp. H366-H381.

[28] W. F. Bluhm, M. Meyer, E. A. Swanson and W. H. Dillmann, "Postrest Potentiation of Active Force in Mouse Papillary Muscles Is Greatly Accelerated by Increased Stimulus Frequency," Annals of New York Academy of Sciences, Vol. 853, 1998, pp. 304-307.

[29] J. Layland and J. C. Kentish, "Positive Force- and $\left[\mathrm{Ca}^{2+}\right]$ i-Frequency Relationships in Rat Ventricular Trabeculae at Physiological Frequencies," American Journal of Physiology, Vol. 276, 1999, pp. H9-H18.

[30] D. M. Bers, "Excitation-Contraction Coupling and Cardiac Force," Kluwer Academic Publishers, Dordrecht, 2002. 
[31] R. A. Bouchard and D. Bose, "Analysis of the IntervalForce Relationship in Rat and Canine Ventricular Myocardium," American Journal of Physiology, Heart and Circulatory Physiology, Vol. 257, No. 6, 1989, pp. H2036H2047.

[32] M. Endoh, "Force-Frequency Relationship in Intact Mammalian Ventricular Myocardium: Physiological and Pathophysiological Relevance," European Journal of Pharmacology, Vol. 500, No. 1-3, 2004, pp.73-86. doi:10.1016/j.ejphar.2004.07.013

[33] Y. Xu, M. M. Monasky, N. Hiranandani, K. M. Haizlip, G. E. Billman and P. M. Janssen, "Effect of Twitch Interval Duration on the Contractile Function of Subsequent Twitches in Isolated Rat, Rabbit, and Dog Myocardium under Physiological Conditions," Journal of Applied Physiology, Vol. 111, No. 4, 2011, pp. 1159-1167. doi:10.1152/japplphysiol.01170.2010

[34] M. M. Monasky and P. M. Janssen, "The Positive ForceFrequency Relationship Is Maintained in Absence of Sarcoplasmic Reticulum Function in Rabbit, But Not in Rat Myocardium," Journal of Comparative Physiology, 179, No. 4, 2009, pp. 469-479.
[35] T. Matsushita, M. Okamoto, J. Toyama, I. Kodama, S. Ito, T. Fukutomi, S. Suzuki and M. Itoh, "Adriamycin Causes Dual Inotropic Effects through Complex Modulation of Myocardial $\mathrm{Ca}^{2+}$ Handling," Japanese Circulation Journal, Vol. 64, No. 1, 2000, pp. 65-71. doi: $10.1253 /$ jcj.64.65

[36] J. Asayama, T. Tatsumi, H. Miyazaki, I. Omori, D. Inoue and M. Nakagawa, "Suppressing Effects of Caffeine on Postextrasystolic Potentiation in Papillary Muscles of Guinea Pigs," Japanese Circulation Journal, Vol. 54, No. 2, 1990, pp. 207-213. doi:10.1253/jcj.54.207

[37] M. Porta, A. V. Zima, A. Nani, P. L. Diaz-Sylvester, J. A. Copello, J. Ramos-Franco, L. A. Blatter and M. Fill, "Single Ryanodine Receptor Channel Basis of Caffeine's Action on $\mathrm{Ca}^{2+}$ Sparks," Biophysical Journal, Vol. 100, No. 4, 2011, 931-938. doi:10.1016/j.bpj.2011.01.017

[38] R. Zucchi, F. Ronca and S. Ronca-Testoni, "Modulation of Sarcoplasmic Reticulum Function: A New Strategy in Cardioprotection," Pharmacology \& Therapeutics, Vol. 89, 2001, pp. 47-65. doi:10.1016/S0163-7258(00)00103-0 